\title{
Degradation Prediction Model for Friction in Highways
}

\author{
Adriana Santos ${ }^{1}$, Elisabete Freitas ${ }^{1}$, Susana Faria ${ }^{2}$, Joel R. M. Oliveira ${ }^{1}$, Ana Maria A. \\ C. Rocha ${ }^{3}$ \\ ${ }^{1}$ Department of Civil Engineering, C-TAC - Territory, Environment and Construction Centre, \\ University of Minho, Portugal \\ asantos@ascendi.pt, \{efreitas, joliveira\}@civil.uminho.pt \\ 2 Department of Mathematics and Applications, CMAT-Centre of Mathematics, University of \\ Minho, Guimarães, Portugal \\ sfaria@math.uminho.pt \\ ${ }^{3}$ Department of Production and Systems, Algoritmi Research Centre, University of Minho, \\ Portugal \\ arocha@dps. uminho.pt
}

\begin{abstract}
The purpose of this paper is to develop a multiple linear regression model that describes the pavement's friction behaviour using a degradation evolution law that also considers the effects of weather, vertical alignment and traffic factors.

This study is based on real data obtained from two different highways with an approximate total length of $43 \mathrm{~km}$. These sections present different alignment features (plan/profile), different Annual Average Daily Traffic and are subjected to different weather conditions. Nevertheless, both comprise the same type of upper layer.

The efficiency of the linear regression model in approaching and explaining data was demonstrated. The most relevant factors involved in the degradation process of pavements' friction were identified.
\end{abstract}

Keywords: Prediction, regression model, friction, highways.

\section{Introduction}

Pavements can become degraded in several ways and their structural and functional status can be described - according to the European project COST 324 - by seven indicators: Longitudinal Profile, Transversal Profile, Surface Cracking, Structural Cracking, Structural Adequacy, Surface Defects and Skid Resistance (friction) [2].

Pavements maintenance conditions are strongly conditioned by a significant number of variables, with several pondering factors. All these variables are inter-related and affect the pavement's entire life cycle, both in terms of functionality and structure. Those variables can be used in pavements degradation models, which are a fundamental component of any pavement management system. These models are based on the study of performance data and establish the evolution law concerning the 
pavements degradation, by determining the relationships between the causes and effects of pavement degradation [11].

The main goal of a degradation model is to characterize the response-variable throughout time, as well as to determine whether this is related with a set of previously selected explanatory variables, such as the age, the traffic, the structure of the pavement and the weather conditions, among others.

In a modelling study of pavements degradation, in each sample unit, both the response-variable and the explanatory variables are constantly monitored. Some of these variables represent fixed characteristics of the sample unit, such as the traffic directions, the kilometric point and the type of lane (left, right and additional); therefore these are time independent explanatory variables, whereas others, such as the temperature and the traffic are time-dependent explanatory variables.

There are several pavement degradation models for the different status indicators, individual or global (that consider the individuals with pondering). Markov's prevision model is an example of a frequently used model of predicting the global conditions of a pavement, due to its ability to include pavement's rehabilitations and degradation rates in one single probability transition matrix [1].

On the other hand, when historical data are insufficient to develop numerical algorithms, non-formulated methods can be used, such as the Intelligent Systems, among which we highlight the artificial neural networks [6] and the adaptive systems (fuzzy) which are another category of modelling techniques [7]. With the combination of both (artificial neural networks and fuzzy systems), a hybrid system arose, named Neurofuzzy System [8].

Nevertheless, in the last decades many progresses have been made in this field, leading to the birth of other prediction models, such as the Nonlinear mixed-effects models that, due the flexibility they provide in handling imperfect data, such as those which are incorrect and/or inconsistent, provide more reliable previsions [10, 14].

Many degradation models have been developed for the longitudinal and transversal profile indicators, as well as for the cracking indicators. However, regarding the friction, few models are presented and even fewer are discussed in terms of modelling, as can be seen in COST 324 [3].

Friction has been acknowledged as one of the main factors contributing to the number of traffic accidents and is therefore essential to the assessment of the pavements quality, integrated within management systems. This indicator is influenced by a large number of parameters, such as the traffic volume and respective driving speed, the pavements characteristics and the grading composition, the precipitation and drainage capacity, as well as the temperature. In a study in the United Kingdom, it was recognized that the level of friction demanded for roads under operation would have to vary along the road, according to its geometry and other factors [13].

The main objective of this study is to describe the pavement's friction behaviour through a multiple linear regression model taking into account the effects of weather, vertical alignment and traffic factors.

The remainder of the paper is organized as follows. Section 2 describes the data, the variables and multiple linear regression models. The statistical analysis of the variable is done in Section 3. The results of applying multiple regression linear mod- 
els to describe the pavement's friction behaviour are presented in Section 4. Finally, we make some concluding remarks in Section 5.

\section{Materials and Methodology}

\subsection{Sample Design}

This study is based on real data obtained from $100 \mathrm{~m}$ pavement sections of two different highway lanes with an approximate total length of $43 \mathrm{Km}$. The first stretch (Section 1) is located in the Northern and the second (Section 2) in the Centre of Portugal. These sections present different alignment features (plan/profile), different Annual Average Daily Traffic (AADT) and are subject to different weather conditions. Nevertheless, both comprise the same type of upper layer.

Each section was monitored for a period of approximately 8 years. The data comprises a total of 3366 observations.

\subsection{The Data}

For the development of this model we considered the variables that mostly influence the pavement's friction degradation, such as the traffic, the weather conditions, the texture and the alignment features, especially in terms of longitudinal profile.

The FRICTION is taken, for modelling purposes, as the dependent variable. This variable represents the component of adherence and friction between the tyre and the pavement surface and is responsible for a significant part of the highway accidents. The value of friction can be expressed in several units, but in this study it was expressed in GN (Grip Number).

The explanatory variables are:

(a) TEXTURE (mm): designated by macro-texture, this corresponds to the texture with a wavelength between 0.5 and $50 \mathrm{~mm}$. This is important since it enables the dispersion of surface water, providing drainage channels. Macro-texture is obtained by the adequate proportion between the grading and the surface mortar or by surface finishing techniques;

(b) Ac.AADT (vehicles): is the accumulated annual average daily traffic (light and heavy vehicles) up to each data acquisition moment;

(c) MAAT $\left({ }^{\circ} \mathrm{C}\right)$ : is the mean of the average air temperature obtained in the month and period referring to the Climatological Normal;

(d) VA: is the vertical alignment (1-Slopes, i; 2- Concave Curves, Ccv; 3-Convex Curves, Ccx), as shown in Fig. 1. 


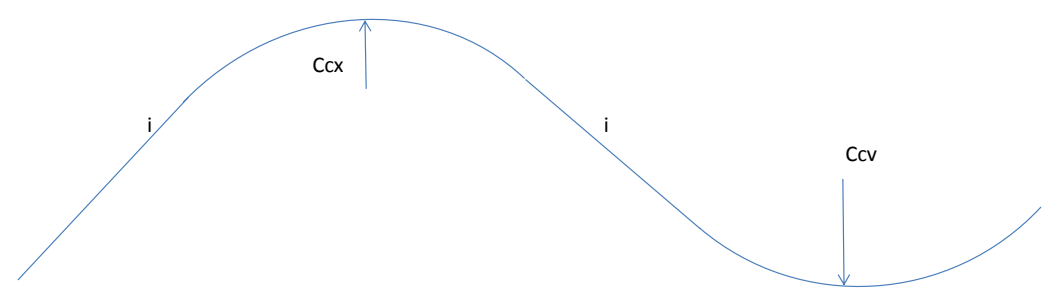

Fig. 1. Vertical Alignment in the highway

\subsection{Statistical Modelling}

Regression analysis is one of the most widely used statistical tools because it provides simple methods for establishing a functional relationship between a response and a set of explanatory variables. It has extensive applications in many subject areas, like medicine, economics, biology, chemistry, engineering, sociology, etc.

Consider the multiple linear regression model

$$
Y=X \beta+\varepsilon
$$

Where $Y$ is an $n \times 1$ vector of response, $X$ is an $n \times k=(p+1)$ full rank matrix of explanatory variables including one constant column, $\beta$ is a $k \times 1$ vector of unknown finite parameters and $\varepsilon$ is an $n \times 1$ vector of i.i.d. random disturbances each of which follows $N\left(0, \sigma^{2}\right)$. We predict the output $Y$ using the least squares method via the model $\hat{Y}=X \hat{\beta}$, where $\hat{\beta}=\left(X^{T} X\right)^{-1} X^{T} Y$.

Considering that the behaviour of friction is closer to the linear when compared with other parameters, such as alligator cracking, in this study we developed a multiple linear regression model that enabled the analysis of the relation between a dependent variable (FRICTION) and a set of explanatory variables, previously described.

The selection of an appropriate subset of explanatory variables to be used in a multiple linear regression model is an important aspect of a statistical analysis. In this study, we applied Stepwise regression which chooses a subset of explanatory variables exploring only a few possible sub-models [9].

These models were estimated using data collected from Section 1, Section 2 and from both sections (Section 1+2). In the model constructed with all data, a binary variable for the section (SECT) was also included.

Since the major role of regression modelling is to predict unknown future samples [5], it may be of interest to estimate their prediction performance. The root meansquared error of prediction (RMSEP) of a model represents its prediction ability. The most common approaches to measure prediction accuracy use resampling. The standard resampling method in this context is cross-validation while bootstrap can be used as an alternative [4]. In this work, we used K-fold cross-validation to estimate the root mean-squared error of prediction.

Data were statistically analyzed using the freeware R, version 2.14.1 [12]. 


\section{$3 \quad$ Statistical Analysis}

For a better understanding of the data under study, a statistical analysis of the continuous variables was initially made. The results are shown in Table 1.

Table 1. - Descriptive Statistics of continuous variables.

\begin{tabular}{clrrrr}
\hline Section & $\begin{array}{c}\text { Descriptive } \\
\text { Statistics }\end{array}$ & $\begin{array}{r}\text { FRICTION } \\
(\mathrm{GN})\end{array}$ & $\begin{array}{c}\text { TEXTURE } \\
(\mathrm{mm})\end{array}$ & $\begin{array}{c}\text { Ac.AADT } \\
(\text { vehicles })\end{array}$ & $\begin{array}{c}\text { MAAT } \\
\left({ }^{\circ} \mathrm{C}\right)\end{array}$ \\
\hline 1 & Minimum & 0.45 & 0.79 & 48945 & 12.0 \\
$(\mathrm{~N}=1580)$ & Maximum & 0.85 & 1.69 & $6.00 \mathrm{E}+06$ & 20.9 \\
& Mean & 0.69 & 1.11 & $3.04 \mathrm{E}+06$ & 16.5 \\
& StdDev & 0.07 & 0.14 & $2.98 \mathrm{E}+06$ & 4.5 \\
\hline 2 & Minimum & 0.35 & 0.79 & 246691 & 8.0 \\
$(\mathrm{~N}=1786)$ & Maximum & 0.84 & 1.85 & $11.88 \mathrm{E}+06$ & 21.0 \\
& Mean & 0.57 & 1.25 & $6.52 \mathrm{E}+06$ & 15.7 \\
& StdDev & 0.11 & 0.22 & $4.74 \mathrm{E}+06$ & 5.1 \\
\hline $1+2$ & Minimum & 0.35 & 0.79 & 48945 & 8.0 \\
$(\mathrm{~N}=3366)$ & Maximum & 0.85 & 1.85 & $11.88 \mathrm{E}+06$ & 21.0 \\
& Mean & 0.62 & 1.19 & $4.89 \mathrm{E}+06$ & 16.1 \\
& StdDev & 0.11 & 0.20 & $4.37 \mathrm{E}+06$ & 4.8 \\
\hline
\end{tabular}

Section 1 showed friction values significantly higher than Section 2 (t-test $=-40.72, \mathrm{p}$-value $<0.001)$. This result may be explained by the fact that Section 2 has a higher accumulated annual average daily traffic (Ac.AADT) than Section 1 (t-test $=21.28, \mathrm{p}$-value $<0.001)$. Furthermore, there is a greater variability of friction in Section 2.

We may also observe that both Sections present a similar maximum value of the mean average air temperature $\left(21.0^{\circ} \mathrm{C}\right)$. However, Section 1 displayed a mean of the average air temperature (MAAT) significantly higher than Section 2 ( $\mathrm{t}$ - test $=-4.55$, p-value < 0.001).

Concerning the texture, Section 1 displayed texture values significantly lower than Section 2 ( $\mathrm{t}$ - test $=25.82$, $\mathrm{p}$-value $<0.001)$.

We studied the presence or absence of an association between each explanatory variable and the dependent variable FRICTION, aiming to reveal the individual predictive capacity of the explanatory variable. For continuous explanatory variables, the correlation coefficient of Pearson was employed and for categorical explanatory variables that of the ANOVA test.

In Table 2, the coefficients of correlation between the variable friction and each of the continuous explanatory variables are presented along with the respective p-value. The variables Ac.AADT and TEXTURE reveal the most significant negative correlation, whereas the variable Mean Average Air Temperature (MAAT) reveals different correlations in Section 1 and Section 2. 
Table 2. - The correlation coefficient for continuous covariates and variable Friction.

\begin{tabular}{lrrr}
\hline Section & TEXTURE & Ac.AADT & MAAT \\
\hline 1 & $-0.490^{* * * *}$ & $-0.831^{* * *}$ & $-0.831^{* * * *}$ \\
2 & $-0.557^{* * *}$ & $-0.871^{* * *}$ & $0.369^{* * *}$ \\
$1+2$ & $-0.609^{* * *}$ & $-0.876^{* * *}$ & $0.021^{* * *}$ \\
\hline
\end{tabular}

The friction distribution per vertical alignment characteristics is shown in Table 3.

Table 3. - Friction distribution per vertical alignment characteristics.

\begin{tabular}{llrrr}
\hline Section & $\begin{array}{l}\text { Descriptive } \\
\text { Statistics }\end{array}$ & Ccv & Ccx & i \\
\hline 1 & N & 88 & 348 & 1144 \\
& & $(5.57 \%)$ & $(22.03 \%)$ & $(72.41 \%)$ \\
& Minimum & 0.55 & 0.53 & 0.45 \\
& Maximum & 0.79 & 0.83 & 0.85 \\
& Mean & 0.69 & 0.69 & 0.69 \\
& Std. Dev & 0.06 & 0.06 & 0.07 \\
\hline 2 & N & 359 & 586 & 841 \\
& & $(20.00 \%)$ & $(32.43 \%)$ & $(47.57 \%)$ \\
& Minimum & 0.35 & 0.36 & 0.35 \\
& Maximum & 0.84 & 0.82 & 0.82 \\
& Mean & 0.56 & 0.56 & 0.56 \\
& Std. Dev & 0.10 & 0.11 & 0.10 \\
\hline \multirow{2}{*}{$1+2$} & N & 447 & 934 & 1985 \\
& & $(13.28 \%)$ & $(27.75 \%)$ & $(58.97 \%)$ \\
& Minimum & 0.35 & 0.36 & 0.35 \\
& Maximum & 0.84 & 0.83 & 0.85 \\
& Mean & 0.59 & 0.61 & 0.64 \\
& Std. Dev & 0.11 & 0.12 & 0.11 \\
\hline
\end{tabular}

The effect of alignment characteristics and sections on FRICTION and their interaction was analyzed by a two-way analysis of variance (ANOVA). Results of the twoway ANOVA showed that the interaction was not significant $(\mathrm{F}=0.117, \mathrm{p}$-value $=$ 0.890).

In the situation of non-significant interaction, a common practice is proceeding by fitting an additive model, whose results are shown in Table 4 . We found no significant differences between the alignment characteristics in terms of FRICTION $(\mathrm{F}=0.405$; $\mathrm{p}$-value $=0.667)$ and, as shown, the mean friction in Section 1 was significantly higher than in Section 2. 
Table 4. - ANOVA table.

\begin{tabular}{lccrr}
\hline Model & Df & $\begin{array}{c}\text { Mean } \\
\text { Square }\end{array}$ & F-value & P-value \\
\hline Section & 1 & 12.080 & 1457.629 & $<0.001$ \\
Alignment & 2 & 0.003 & 0.405 & 0.667 \\
Error & 3362 & 0.008 & 0.53 & 0.45 \\
\hline
\end{tabular}

\section{$4 \quad$ Results}

Table 4 indicates the estimates of the parameters for the three multiple linear regression models. For each model, the adjusted coefficient of determination $R_{a}^{2}$ is also computed. To measure prediction error in these models, we used the average of 2000 random 5-fold cross-validation runs.

In all models, the included explanatory variables are highly significant. We also found that when the texture and accumulated annual average daily traffic increase, in average the friction value decreases. As expected, we observed that the vertical alignment does not influence FRICTION.

As can be seen in Table 5, the quality of fit of the models is good $\left(0.693<R_{a}^{2}<0.826\right)$. We also can observe that the prediction performance of three models is similar.

Table 5. - Estimated parameters.

\begin{tabular}{|c|c|c|c|c|c|c|}
\hline \multirow[b]{2}{*}{ Variable } & \multicolumn{2}{|c|}{ Section 1} & \multicolumn{2}{|c|}{ Section 2} & \multicolumn{2}{|c|}{ Section $1+2$} \\
\hline & Estimate & StdError & Estimate & StdError & Estimate & StdError \\
\hline Constant & $0.784^{* * * *}$ & 0.008 & $0.771^{* * * *}$ & 0.010 & $0.742^{* * * *}$ & 0.007 \\
\hline TEXTURE & $-0.034^{* * * *}$ & 0.008 & $-0.039^{* * * *}$ & 0.007 & $-0.035^{* * *}$ & 0.006 \\
\hline Ac.AADT & $-1.83 \mathrm{E}-08^{* * *}$ & $3.79 \mathrm{E}-10$ & $-1.96 \mathrm{E}-08^{* * * *}$ & $3.42 \mathrm{E}-10$ & $-9.30 \mathrm{E}-09^{* * *}$ & $2.46 \mathrm{E}-10$ \\
\hline MAAT & & & $-0.002^{* * *}$ & $2.78 \mathrm{E}-04$ & $-1.00 \mathrm{E}-03^{* *}$ & $1.87 \mathrm{E}-04$ \\
\hline \multicolumn{7}{|l|}{ SECT(ref.:1) } \\
\hline 2 & & & & & $-0.056^{* * *}$ & 0.002 \\
\hline \multicolumn{7}{|l|}{ Summary } \\
\hline \multicolumn{7}{|l|}{ Statistics } \\
\hline$R_{a}^{2}$ & 0.693 & & 0.767 & & 0.826 & \\
\hline RMSEP & 0.048 & & 0.051 & & 0.053 & \\
\hline
\end{tabular}

** Denotes the significance at the 0.01 level

*** Denotes the significance at the 0.001 level

Plots of the residuals are widely used to assess the adequacy of a regression model. Figure 2 provides the QQ-plot of the standardized residuals of the three models, which indicate that the standardized residuals follow normal distribution. The normal- 
ity test computed for each model (Shapiro-Wilks) also does not lead to reject the null Hypothesis.

Figure 3 shows the standardized residuals versus fitted values. This panel does not show any pattern in the spread of the residuals and we concluded that homogeneity assumption is verified.

We also constructed standardized residuals versus each explanatory variable to check independence assumption and we found no residual patterns.

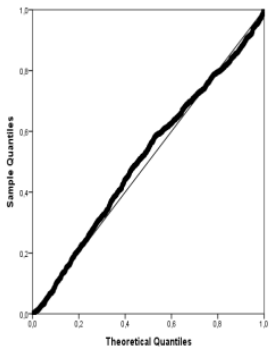

Section 1

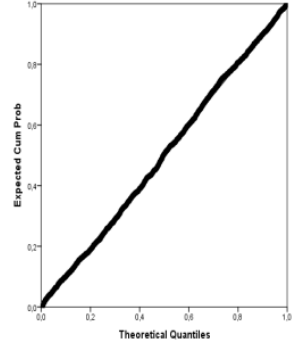

Section 2

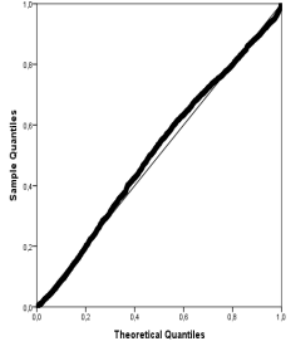

Section $1+2$

Fig. 2. QQ-Plot of the standardized residuals

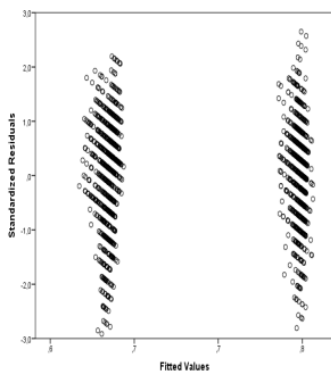

Section 1

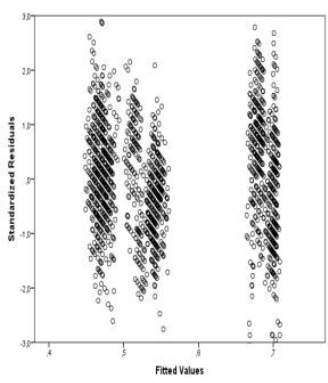

Section 2

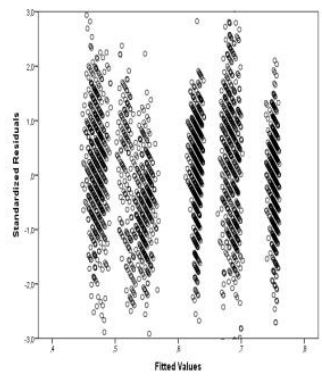

Section $1+2$

Fig. 3. Standardized residuals versus fitted values

\section{Conclusions}

For the real data available, this study developed a multiple regression model that describes the prevision of the pavements' friction degradation and identifies the effects of various factors upon its behaviour. 
This study also revealed the efficiency of the linear regression model in approaching and explaining that data, especially with regard to the identification of the most relevant factors involved in the evolution process of pavements' friction.

In the future, mixed-effects models will be applied to the data used in this paper taking into account that the data comprise a series of test results measured throughout the time.

Acknowledgements. This research was financed by FEDER Funds through "Programa Operacional Factores de Competitividade - COMPETE" and by Portuguese Funds through FCT -"Fundação para a Ciência e a Tecnologia", within the Projects PEst-OE/MAT/UI0013/2014, PEst-OE/ECI/UI4047/2014 and PEstOE/EEI/UI0319/2014. The authors would also like to thank AdI - Innovation Agency, for the financial support awarded through POFC program, for the R\&D project SustIMS - Sustainable Infrastructure Management Systems (FCOMP-010202-FEDER-023113).

\section{References}

1. Abaza, K., Ashur, S.: Optimum decision policy for management of pavement maintenance and rehabilitation. Transp. Res. Record. 1655, 8-15 (1999)

2. Agardh, S.: Rut Depth Prediction on Flexible Pavements, Calibration and Validation of Incremental-Recursive Models. PhD Thesis, Lunds University, Sweden (2005)

3. COST Action 324: Long Term Performance of Road Pavements, Final Report of the Action. European Commission (1997)

4. Efron, B.: Estimating the Error Rate of a Prediction Rule: Improvement on Crossvalidation. J. Am. Stat. Assoc. 78, 316-331 (1983)

5. Faber, K., Kowalski, B.R.: Propagation of measurement errors for the validation of prediction obtained by principal component regression and partial least squares. J. Chemometr. 11, 181-238 (1997)

6. Freitas, E.: Contribuição para o desenvolvimento de modelos de comportamentos dos pavimentos rodoviários flexíveis - fendilhamento com origem na superfície. $\mathrm{PhD}$ Thesis, Universidade do Minho, Portugal (in Portuguese) (2004)

7. Falcão, D.: Conjuntos, Lógica e Sistemas Fuzzy, Technical report, Instituto Alberto Luiz Coimbra de Pós-Graduação e Pesquisa de Engenharia, COPPE/UFRJ, Brazil (in Portuguese) (2002)

8. Huamaní, I.: Sistemas Neurais Fuzzy Aplicados em Identificação e Controle de Sistemas, MSc Thesis, Faculdade de Engenharia Elétrica e de Computação, Universidade Estadual de Campinas (in Portuguese) (2003).

9. Miller A. J.: Selection of subsets of regression variables (with discussion), J. R. Stat. Soc., 147(A), 389-425 (1984)

10. Lorino, T., Lepert, P., Marion, J., Khraibani, H.: Modeling the road degradation processs: non-linear mixed effects models for correlation and heteroscedasticity of pavement longitunal data, Procedia Soc. Behav. Sci., 48, 21-29 (2012)

11. Pereira, P., Picado-Santos, L.: Pavimentos rodoviários, Barbosa \& Xavier, Braga, Portugal (in Portuguese) (2002) 
12. R Development Core Team: R: A Language and Environment for Statistical Computing. R Foundation for Statistical Computing, Vienna, Austria (2014)

13. Sinhal, R.: The Implementation of a Skid Policy to Provide the Required Friction Demand on the Main Road Network in the United Kingdom. Highways Agency, UK, (2004)

14. Yuan, X., Pandey, M.: A nonlinear mixed-effects model for degradation data obtained from in-service inspections. Reliab. Eng. Syst. Safe., 94, 509-519 (2009) 